2 Molecularly Imprinted Protein Recognition Thin Films Constructed by

\title{
Controlled/Living Radical Polymerization
}

4

5

6

7

8

9 10 11

12 13 14 \section{(1)}

5

Shogo Sasaki, Tooru Ooya, Yukiya Kitayama, Toshifumi Takeuchi*

Graduate School of Engineering, Kobe University, 1-1, Rokkodai-cho, Nada-ku, Kobe, 657-8501, Japan

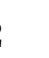

3

4

Running title: Protein imprinting by ATRP

(6)

KEYWORDS: Molecular Imprinting; Controlled/living Radical Polymerization; Proteins

* To whom correspondence should be addressed.

Phone: +81-78-803-6158. Fax: +81-78-803-6158

E-mail: takeuchi@gold.kobe-u.ac.jp 
2 We demonstrated the synthesis of molecularly imprinted polymers (MIPs) with binding affinity

3 toward a target protein, ribonuclease A (RNase) by atom transfer radical polymerization (ATRP) of

4 acrylic acid, acrylamide, and $N, N^{\prime}$-methylenebisacrylamide in the presence of RNase. The binding

5 activity of the MIPs was evaluated by surface plasmon resonance (SPR) of the MIP thin layers

6 prepared on the gold-coated sensor chips. The MIPs prepared by ATRP (MIP-ATRP) had a binding

7 affinity toward RNase with larger binding amount compared to MIPs prepared by conventional free

8 radical polymerization methods (MIP-RP). Moreover, protein selectivity was evaluated using

9 reference proteins (cytchrome c, myoglobin, and $\alpha$-lactalbumin) and was confirmed in MIP-ATRP

10 of optimum film thickness determined experimentally to be $15-30 \mathrm{~nm}$; however, protein selectivity

11 was not achieved in all MIP-RP. We have shown that ATRP is powerful technique for preparing

12 protein recognition materials by molecular imprinting. 


\section{Introduction}

Molecular recognition materials for proteins are of great importance in the field of life science, especially for use in protein separation, proteomics and diagnosis of cancers and other intractable diseases (1). Currently, biomolecules such as enzymes, antibodies, and aptamers are used as molecular recognition materials for proteins. Although highly selective binding activity can be achieved, such biomolecules are difficult to control in production as well as being unstable in harsh conditions and easily denatured. Polymer-based artificial molecular receptors serve as a more stable and versatile alternative for application to explore protein-ligand interaction in biological systems.

Molecular imprinting, a template polymerization technique, is a powerful method for preparing artificial receptors bearing predetermined binding cavities capable of recognizing target molecules.

Molecularly imprinted polymers (MIPs) are obtained by the co-polymerization of functional monomers and crosslinkers in the presence of a target molecule or its derivative (template molecule) (2-7). When proteins are selected as the template molecules for MIPs, the complementary binding cavities left in the polymer matrices after removal of the templates are capable of selective protein binding according to size and chemical properties, depending upon the functional monomers used (6). In other words, the conformation of complexes formed between the template proteins and functional monomer(s) during the polymerization step of preparing MIPs is critical for the development of highly selective binding activity with strong affinity for the target protein. Previously, conventional free radical polymerization (RP) was employed for the 
Controlled/living radical polymerization (CLRP) is a powerful technique for the synthesis of well-defined polymers with narrow molecular weight distribution or complex molecular architectures such as block or star polymers (10-13). Many kinds of CLRP techniques have been discovered and developed, but atom transfer radical polymerization (ATRP) is one of most studied and highly developed of these techniques, involving radical species that are reversibly generated by the redox reaction of copper ions. It is known that CLRP can be used to synthesize more

9 homogeneous cross-linking materials compared to those synthesized via RP $(8,14)$. Accordingly, CLRP was applied to synthesize MIPs in order to improve the uniformity of molecular recognition

11 sites as well as recognition ability. example, Ye et al. reported that MIPs prepared by nitroxide-mediated living radical polymerization displayed more highly selective cholesterol binding compared to those prepared by RP (15). In our previous work, we also tried using reverse ATRP with $\mathrm{CuCl}_{2}$ and a thermal initiator in organic solvents to synthesize the MIPs containing molecular recognition site for bisphenol A (BPA), which is believed to be an endocrine disruptor that binds to estrogen receptors (16). It was discovered that the MIPs obtained by ATRP had high recognition ability toward BPA compared to those obtained by conventional free radical polymerization. Moreover, very recently Byrne et al. 
1 investigated the role of CLRP in the formation of imprinted polymers in detail as well as elucidated that

2 binding activity was clearly increased when using CLRP in place of RP methods (17). MIPs for

3 protein recognition were also prepared by CLRP. Gai and coworkers prepared protein-imprinted

$4 \quad$ MIP by ATRP for protein separation (18). However, the effectiveness of the CLRP on the protein

5 recognition ability has not been discussed compared to RP.

6 In this study, we synthesized MIPs toward ribonuclease A (RNase) by activators generated by

7 electron transfer (AGET) ATRP $(19,20)$ (henceforth referred to as MIP-ATRP) in an aqueous

8 solution. In order to prepare MIPs bearing selective binding cavities, acrylic acid, which is often

9 used as a functional monomer for basic compounds, was introduced into a solution containing

10 RNase to form complexes with the protein molecules via electrostatic interactions and/or hydrogen

11 bonding. After the addition of a crosslinker, $N, N^{\prime}$-methylenebisacrylamide (MBAA), AGET ATRP

12 of these monomers were carried out from 2-bromo-2-methylpropionic acid (ATRP

13 initiator)-immobilized gold surfaces of either a quartz crystal microbalance (QCM) or surface

14 plasmon resonance (SPR) sensor chips. QCM measurements were performed to estimate the

15 thickness of the MIP films, and the binding activity of the MIPs was evaluated by SPR

16 measurements. In order to compare the ATRP-based method with conventional radical

17 polymerization, RP-based MIPs (MIP-RP) were prepared on 2,2'-azobis(2-methylpropionamidine)

18 (V-50)-immobilized substrates, and the comparative effectiveness of AGET ATRP for the

19 formation of selective binding cavities in MIP thin films was discussed. 
3 RNase, ascorbic acid, $\mathrm{CuBr}_{2}$, dichloromethane $\left(\mathrm{CH}_{2} \mathrm{Cl}_{2}\right), 4,4$ '-dimethylaminopyridine (DMAP),

4 tetra-sodium ethylenediamine tetraacetate (EDTA-4Na), sodium chloride $(\mathrm{NaCl})$, sodium hydroxide

$5 \quad(\mathrm{NaOH})$, ethanol, methanol, critic acid, 4-(2-hydroxyethyl)-1-piperazineethanesulfonic acid

6 (HEPES) were purchased from Nacalai Tesque Co. Ltd (Kyoto, Japan). Acrylic acid, V-50, MBAA,

7 acryl amide were purchased from Wako Pure Chemical Industries, Ltd (Osaka, Japan).

$8 \quad N, N, N^{\prime}, N^{\prime \prime}, N^{\prime n}$-Pentamethyldiethylenetriamine (PMDETA), N-hydroxy succinimide (NHS),

9 11-mercapto-1-undecanol, 11-mercapto-1-undecanoic acid, cytochrome c, miyoglobin,

10 a-lactalbumin were purchased from Sigma-Aldrich (MO, USA).

11 1-Ehtyl-3-(3-dimethylaminopropyl)carbodiimide hydrochloride (EDC) was purchased from Peptide

12 Institute Inc. (Osaka, Japan) and 2-bromo-2-methylpropionicacid was purchased from Tokyo

13 Chemical Industry (Tokyo, Japan). $\mathrm{CH}_{2} \mathrm{Cl}_{2}$ was purified by distillation prior to use in order to

14 remove water. V-50 was used without further purification.

Preparation of MIP thin films by AGET ATRP (MIP-ATRPS) 
$\mathrm{mg}, 5 \mu \mathrm{mol})$ in ethanol $(1 \mathrm{~mL})$ for $1 \mathrm{~h}$. The QCM chips were washed by ethanol and dried in vacuo. The QCM chips were then dipped in 2-bromo-2-methylpropionicacid (3.26 mg, $20 \mu \mathrm{mol})$, DMAP (3.66 mg, $35 \mu \mathrm{mol})$ and EDC (5.66 mg, $35 \mu \mathrm{mol})$ in $\mathrm{CH}_{2} \mathrm{Cl}_{2}(1 \mathrm{~mL})$ for $2 \mathrm{~h}$, and the QCM chips were washed by $\mathrm{CH}_{2} \mathrm{Cl}_{2}$ and dried in vacuo. Frequency of the QCM chips was measured by using Quartz Crystal Analyzer QCA 917 (SEIKO EG\&G Co. Ltd., Tokyo, Japan). The concentration of 2-bromo-2-methylpropionicacid was changed from $0.2 \mu \mathrm{mol}$ to $20 \mu \mathrm{mol}$.

MIP thin films were prepared by AGET ATRP as follows: RNase $(13.4 \mathrm{mg},(1 \mu \mathrm{mol}))$, acryl 8 amide $(0.27 \mathrm{mg}, 3.75 \mu \mathrm{mol})$, acrylic acid $(0.26 \mathrm{mg}, 3.75 \mu \mathrm{mol})$, MBAA $(7.7 \mathrm{mg}, 50 \mu \mathrm{mol}), \mathrm{CuBr}_{2}$ (0.94 mg, $4 \mu \mathrm{mol})$, PMDETA $(1.38 \mathrm{mg}, 8 \mu \mathrm{mol})$ were dissolved in a HEPES-NaOH buffer (pH 7.4) in a polystyrene (PS) container. The QCM chips were set in a teflon cell (dip type) and dipped in the PS container. As soon as ascorbic acid $(3.2 \mathrm{mg}, 12 \mu \mathrm{mol})$ was added in the PS container, it was sealed by a septum. After degassing the solution by vacuum/nitrogen cycles, the PS container was set in thermostat bath at $40{ }^{\circ} \mathrm{C}$. After quenching polymerization at appropriate polymerization time by air, the QCM chips were dipped in $1 \mathrm{M} \mathrm{NaCl}$ aqueous solution ( $\mathrm{NaCl}$ aq.) for $1 \mathrm{~h}$ to remove RNase. In order to remove the copper ions, the QCM chips were subsequently dipped in $1 \mathrm{M}$ EDTA-4Na aqueous solution (EDTA-4Na aq.) for $24 \mathrm{~h}$. The frequencies of QCM chips were measured both after polymerization and washing with $\mathrm{NaCl}$ aq.. The film thickness was calculated by the following formula:

$$
\text { Film thickness }(\mathrm{nm})=\frac{\text { deposits of PMBAA }(\mathrm{ng})}{\text { density of PMBAA }\left(1.23 \times 10^{-12} \mathrm{ng} / \mathrm{nm}^{3}\right) \times \text { surface area of quartz }\left(0.196 \times 10^{14} \mathrm{~nm}^{2}\right)}
$$



.

$※$ deposits of PMBAA $(\mathrm{ng})=$ change of frequency $\left(\mathrm{s}^{-1}\right) \times$ surface area of quartz $\left(0.196 \mathrm{~cm}^{2}\right) \times\left(\frac{\sqrt{\mathrm{u} \times \rho}}{2 \times \mathrm{F}_{0}^{2}} \times\right.$ surface area of quartz

$\left(\mathrm{F}_{0}\right.$; fundamental frequency $\left(9003304 \mathrm{~s}^{-1}\right)$, surface area; $0.196 \mathrm{~cm}^{2}$, $\mathrm{u}$; shear stress of quartz $\left(2.947 \times 10^{20} \mathrm{ng} / \mathrm{cm} \cdot \mathrm{s}^{2}\right), \rho$; density of quartz

\section{Preparation of MIP thin films by RP (MIP-RPS)}

The immobilization of initiator for conventional radical polymerization on the QCM chips were

carried out as follow. The QCM chips were cleaned by $\mathrm{UV}-\mathrm{O}_{3}$ treatment for 20 min and dipped in ethanol solution $(1 \mathrm{~mL})$ containing 11-mercapto-1-undecanoic acid (1.05 mg, $5 \mu \mathrm{mol})$ for $1 \mathrm{~h}$. After washing the QCM chips by ethanol and drying in vacuo, the QCM chips were dipped in ethanol solution $(1 \mathrm{~mL})$ containing NHS $(1.98 \mathrm{mg}, 20 \mu \mathrm{mol})$ and EDC $(3.26 \mathrm{mg}, 10 \mu \mathrm{mol})$ for $1 \mathrm{~h}$.

The QCM chips were washed by ethanol and dried in vacuo, and the QCM chips were dipped in methanol solution $(1 \mathrm{~mL})$ of $\mathrm{V}-50(2.7 \mathrm{mg}, 10 \mu \mathrm{mol}) .(21)$ The QCM chips were washed by methanol and dried in vacuo. The frequency of the QCM chips was measured at each stage of modification.

The MIP-RPs were prepared by conventional radical polymerization as follows: RNase (13.4 mg, (1 $\mu \mathrm{mol})$ ), acryl amide $(0.27 \mathrm{mg}, 3.75 \mu \mathrm{mol})$, acrylic acid $(0.26 \mathrm{mg}, 3.75 \mu \mathrm{mol})$, MBAA $(7.7 \mathrm{mg}$, $50 \mu \mathrm{mol})$ were dissolved in a HEPES-NaOH buffer ( $\mathrm{pH}$ 7.4) in the PS container. Then, the QCM chips were set in Teflon cell (dip type) and dipped in the PS container. After sealing the PS container by septum and degassing the solution by vacuum/nitrogen cycles, the PS container was set in thermostat bath at $50{ }^{\circ} \mathrm{C}$. After quenching the polymerization at appropriate polymerization 
1 times by washing with pure water, the QCM chips were dipped in $1 \mathrm{M} \mathrm{NaCl}$ aq. for $1 \mathrm{~h}$ to remove

2 RNase. The frequency of the QCM chips was measured after the polymerization and the $\mathrm{NaCl}$ aq.

3 treatment, respectively, and the film thickness was calculated. Surface morphology of the QCM

4 chips after washing treatments was examined by Scanning Electron Microscopy (VE-9800,

5 KEYENCE Co. Ltd).

Preparation of MIP thin films by AGET ATRP on SPR chips

Immobilization of the ATRP initiator on SPR chips (SIA Kit Au (Biacore 3000, Biacore Co. Ltd))

were carried out under the same conditions as the QCM chips. A non-imprinted polymer film

(NIP-ATRP) was also prepared by the above-mentioned procedure without RNase.

Preparation of MIP thin films by RP on SPR chips

Immobilization of the initiator for conventional radical polymerization on SPR chips were carried out under the same conditions as the QCM chips. A non-imprinted polymer film (NIP-RP) was also prepared by the above-mentioned procedure without RNase. using a surface plasmon resonance sensing system (BIACORE 3000, Biacore AB, Sweden). Four 
1 kinds of different proteins (RNase, cytochrome c, myoglobin, and $\alpha$-lactalbumin) were dissolved in

2 a HEPES-NaOH buffer $(\mathrm{pH} 7.4)$ at $25^{\circ} \mathrm{C}$. The conditions of SPR measurements were as follows:

3 running buffer; $10 \mathrm{mM}$ HEPES-NaOH buffer ( $\mathrm{pH} 7.4,20 \mu \mathrm{L} / \mathrm{min}$ ), injection volume; $20 \mu \mathrm{L}$,

4 regeneration solution; $10 \mathrm{mM}$ HEPES-NaOH buffer containing $1 \mathrm{M} \mathrm{NaCl}$ and $5 \mathrm{mM} \mathrm{NaCl}$ aq..

5 The amounts of bound proteins were calculated by measuring the signal intensity at $120 \mathrm{~s}$ after the

6 end of each sample introduction period. Protein concentrations were varied from 0.25 to $5.0 \mu \mathrm{M}$.

7 Binding isotherms were drawn by using the $\Delta \mathrm{RU}$ at each protein concentration. The binding

8 constants and the number of binding sites were calculated by Scatchard plots from the obtained

9 binding isotherms.

Surface characterization using Scanning Electron Microscopy (SEM)

Surface morphology of the obtained QCM chips was examined by Scanning Electron Microscopy (VE-9800, KEYENCE Co. Ltd).

\section{Results and Discussion}

Fig. 1(a) shows MIP-ATRP film thicknesses at different AGET ATRP polymerization times on

QCM chips, where a self-assembled monolayer (SAM) of 11-mercapto-1-undecanol was formed on

QCM chips via strong chemical binding between the gold surface and thiol groups, and the hydroxy end groups were coupled with various concentrations $(0.02,2.0$, and $20 \mathrm{mM})$ of 
1 2-bromo-2-methylpropionic acid in the presence of EDC and DMAP. Film thickness increased

2 linearly with polymerization time on all QCM chips for each different concentration of

3 2-bromo-2-methylpropionic acid, indicating that the "living" nature was maintained throughout

4 polymerization. In addition, somewhat greater film thickness was obtained overall at higher

5 concentrations of 2-bromo-2-methylpropionic acid. According to these results, the film thickness

6 could be controlled not only by polymerization time but also by changing the concentration of

7 2-bromo-2-methylpropionic acid used for immobilization on the chip.

8 We also investigated the polymer film thickness at different polymerization times for RP, where

9 a SAM of 11-mercapto-1-undecanoic acid was formed onto QCM chips, followed by amine coupling with $10 \mathrm{mM}$ of V-50 in the presence of EDC and NHS (21). The MIP-RP film thickness

11 increased up to approximately $50 \mathrm{~nm}$ after only $2 \mathrm{~h}$ and then gradually increased to $84 \mathrm{~nm}$ over $24 \mathrm{~h}$

12 (Fig. 1b). SEM images of the MIP-RP films at each polymerization time supported the rapid increase of the film thickness compared to the MIP-ATRP films. (Supplementary data Fig. S1 and

14 Fig. S2 ).

The differing behavior of polymer growth between MIP-ATRP and MIP-RP is the result of the different polymerization mechanisms that take place in each method. In AGET ATRP, the polymer chain length increases gradually with increase of conversion; on the other hand, in RP the polymer chains propagate dramatically in just a few seconds. From these results, we therefore surmised 
1 that the film thickness could be controlled precisely by applying AGET ATRP for different

2 polymerization times and the initiator density on the substrates, whereas this level of control would

3 be difficult in RP for film thicknesses under $50 \mathrm{~nm}$.

acrylic acid, acrylamide, and MBAA as the fuctional monomer, the co-monomer, and the crosslinker,

respectively. Polymerization was followed by the removal of RNase by washing with $1 \mathrm{M} \mathrm{NaCl}$ aq.

7 to form selective binding cavities, the successful formation of which was confirmed by the reduced

8 mass on the sensor chip (Fig. 2). Thus obtained MIP-ATRP thin films were subsequently washed

9 with EDTA-4Na aq. to remove copper ions; the red color associated with the presence of copper complexes completely disappeared after the EDTA-4Na aq. treatment. Moreover, the mass on the

11 chip after washing with EDTA-4Na aq. clearly decreased (Fig. 2), indicating that the template RNase and copper ions were successfully removed from the MIP-ATRP thin films.

In order to investigate the effect of ATRP on binding activity, binding experiments on MIP-ATRP and MIP-RP were performed by SPR sensors, where MIP-ATRP and MIP-RP were prepared on SPR sensor chips in the same manner with that on QCM chips. When RNase was injected on each chip in a concentration dependent manner, $\triangle R U$ values on the MIP-ATRP chip were found to be larger than those on the MIP-RP (Fig. 3), indicating that the binding activity of the MIP thin films 
$1 \mathrm{fmol} / \mathrm{g})$ instead of RP (45 fmol/g), however the binding constants were similar in those cases $(6.9 \mathrm{x}$

$2 \quad 10^{5} \mathrm{M}^{-1}$ for MIP-ATRP and $7.0 \times 10^{5} \mathrm{M}^{-1}$ for MIP-RP).

3

Selectivity of MIP-ATRP was examined by measuring SPR response for RNase $(14 \mathrm{kDa}, \mathrm{p} I=$ 8.6), cytchrome c (Cyt; $12 \mathrm{kDa}, \mathrm{p} I=10.1)$, myoglobin (Myo; $18 \mathrm{kDa}, \mathrm{p} I=8.2)$, and $\alpha$-lactalbumin (Lac; $14 \mathrm{kDa}, \mathrm{p} I=4.5$ ). When thin films were prepared on the SPR chips with polymerization times of $3 \mathrm{~h}, 4.5 \mathrm{~h}$, and $6 \mathrm{~h}$, and a 2-bromo-2methylpropionic acid concentration of $0.02 \mathrm{mM}$ (MIP-ATRP-002), the binding activities of Myo and Lac were small and negligible compared with those of Cyt and RNase (Fig. 4). Because acrylic acid was used as the functional monomer, Lac, an acidic protein, could not interact with MIP-ATRP due to electrostatic repulsion. Myo is a weak basic protein, therefore weak interactions may have occurred, but they were not strong enough to bind Myo tightly. MIP-ATRP prepared with the polymerization time of $3 \mathrm{~h}$ showed weak binding to Cyt and RNase (Fig. 4a), suggesting that the binding cavities may not have been completely formed. However, the binding activity of Cyt and RNase significantly increased with polymerization time, i.e. the number of active binding cavities increased with film thickness. The binding activity of RNase was larger than that of Cyt when MIP-ATRP was prepared with the polymerization time of $4.5 \mathrm{~h}$ (Fig. $4 \mathrm{~b}$ ). In the case of $6 \mathrm{~h}$ polymerization, the binding activity of RNase was smaller than that of Cyt (Fig. 4c). This may be due to an increase in non-specific binding to the polymer matrix. These results suggest that under the conditions of $0.02 \mathrm{mM}$ 
1 2-bromo-2methylpropionic acid and an AGET ATRP polymerization time of $4.5 \mathrm{~h}$ (resulting in a

2 film thickness of approximately $20 \mathrm{~nm}$ ), larger binding amounts toward RNase among the proteins

3 was observed.

We also investigated the protein selectivity of MIP-ATRP toward RNase using SPR chips prepared with a higher concentration of 2-bromo-2-methyl propionic acid (20 mM) (MIP-ATRP-20). The protein selectivity of MIP-ATRP prepared with $3 \mathrm{~h}, 6 \mathrm{~h}$ and $12 \mathrm{~h}$ polymerization times were

8 shown in Fig. 5. As was the case with MIP-ATRP-0.02, the binding selectivity for both Myo and

9 Lac was small and negligible. Interestingly, binding selectivity for RNase was only observed

10 when the polymerization time was $3 \mathrm{~h}$, where the film thickness was estimated to be approximately

$1130 \mathrm{~nm}$ (Fig. 5a). Because polymer chains propagate gradually in AGET ATRP with conversion, these results imply that selective binding cavities toward RNase were formed in the early stages of

13 polymerization whereas non-specific binding sites seem to form in the later stages. Ergo, it is clear that MIP-ATRP films must be the appropriate thickness in order to display the selectivity toward RNase, and the present study indicates that this optimal thickness is $15-30 \mathrm{~nm}$.

The imprinting effect of MIP-ATRP was confirmed by the comparison with non-imprinted polymer (NIP) thin film prepared by AGET ATRP in a similar manner in the absence of RNase. The selective binding property toward RNase was not confirmed in NIP-ATRP, which was prepared 
1 for $3 \mathrm{~h}$ polymerization on the SPR chip treated with $20 \mathrm{mM}$ 2-bromo-2-methylpropionic acid

2 (Supplementary data Fig. S3). Similarly, when NIP-ATRP was prepared for $4.5 \mathrm{~h}$ polymerization

3 on SPR chip treated with $0.02 \mathrm{mM}$ 2-bromo-2-methylpropionic acid, the selectivity toward RNase

4 was not observed (Supplementary data Fig. S4). These results indicated that the imprint cavities

5 were successfully formed during the imprinting process in MIP-ATRPs, and RNase was recognized

6 by the imprint cavities of the resultant MIP-ATRPs.

$7 \quad$ The selectivity of MIP-RP was also examined to confirm the effectiveness of AGET ATRP as a

8 preparation method of protein-imprinted MIPs (Fig. 6). As seen with MIP-ATRP, the binding

9 activities of Myo and Lac were low, as expected. However, MIP-RPs prepared with

10 polymerization times of $3 \mathrm{~h}$ (Fig. 6a), $6 \mathrm{~h}$ (Fig. 6b) and $12 \mathrm{~h}$ (Fig. 6c) all consistently showed no

11 binding specificity for RNase, indicating that effective binding cavities were not formed in MIP-RP.

12 According to these results, ATRP was proven to be an effective technique to prepare 13 protein-imprinted MIPs.

In conclusion, we demonstrated the preparation of MIPs bearing binding property toward for

RNase on initiator-immobilized gold surfaces by AGET ATRP of acrylic acid, acryl amide, and

MBAA in the presence of RNase. Binding properties were evaluated by SPR measurements, and 
1 around $30 \mathrm{~nm}$, which may be the result of the density gradation of RNase binding cavities in the

2 MIP-ATRP thin films, i.e. because the binding cavities formed at the early stages of ATRP

3 polymerization due to the adsorption of RNase-acrylic acid conjugates onto the

4 initiator-immobilized surface of SPR sensor chips. The results from this study suggested that the

5 parameters affecting the binding activity of MIPs are not limited to the selection of reactant species

6 (functional monomers, co-monomers, and crosslinkers) but also include polymer film thickness, an

$7 \quad$ attribute controllable in AGET ATRP by varying polymerization time and the density of the initiator

8 on the substrates. We expect that CLRP techniques will be applied more frequently in future

9 studies in order to prepare MIPs with high affinity and selectivity towards target proteins, and we

10 believe that the present study will prove valuable in the pursuit of this exciting direction in the field

11 of molecularly imprinted polymers.

\section{Acknowledgements}

This work was partially supported by JSPS KAKENHI Grant Number 18350087.

\section{References}

1. Babine, R.E. and Bender, S.L.: Molecular recognition of protein-ligand complexes: Applications to drug design. Chemical Reviews 97, 1359-1472 (1997).

2. Sellergren, B. Molecularly Imprinted Polymers. (Elsevier, Amsterdam; 2000).

3. Komiyama, M. Takeuchi, T. Mukawa, T. and Asanuma H.: Molecular Imprinting (Wiler-VCH, Weinheim; 2004).

4. Zimmerman, S.C. and Lemcoff, N.G.: Synthetic hosts via molecular imprinting - are 
universal synthetic antibodies realistically possible? Chem. Commun., 5-14 (2004).

5. Haupt, K. and Mosbach, K.: Molecularly imprinted polymers and their use in biomimetic sensors. Chemical Reviews 100, 2495-2504 (2000).

6. Takeuchi, T. and Hishiya, T.: Molecular imprinting of proteins emerging as a tool for protein recognition. Org. Bio. Chem. 6, 2459-2467 (2008).

7. Zu, B.Y., Pan, G.Q., Guo, X.Z., Zhang, Y. and Zhang, H.Q.: Preparation of Molecularly Imprinted Polymer Microspheres via Atom Transfer Radical Precipitation Polymerization. Journal of Polymer Science Part a-Polymer Chemistry 47, 3257-3270 (2009).

8. Ide, N. and Fukuda, T.: Nitroxide-controlled free-radical copolymerization of vinyl and divinyl monomers. 2. Gelation. Macromolecules 32, 95-99 (1999).

9. Kamon, Y., Matsuura, R., Kitayama, Y., Ooya, T. and Takeuchi, T. Precisely Controlled Molecular Imprinting of Glutathione-s-Transferase by Orientated Template Immobilization Using Specific Interaction with an Anchored Ligand on a Gold Substrate. Polymer Chemistry In press (DOI:10.1039/C4PY00350K).

10. Wang, J.S. and Matyjaszewski, K.: Controlled Living Radical polymerization - Atom Transfer Radical Polymerization in the Presence of Transition Metal Complexes. J. Am. Cem. Soc. 117, 5614-5615 (1995).

11. Hawker, C.J., Frechet, J.M.J., Grubbs, R.B. and Dao, J.: Preparation of Hyperbranched and Star Polymers by a Living Self-Condensing Free-Radical Polymerization, J. Am. Cem. Soc. 117, 10763-10764 (1995).

12. Chiefari, J. Chong, Y. K., Ercole, F., Krstina, J., Jeffery, J., Le, T. P. T., Mayadunne, R. T. A., Meijs, G. F., Moad, C. L., Moad, G., Rizzardo, E., and Thang, S. H.: Living free-radical polymerization by reversible addition-fragmentation chain transfer: The RAFT process. Macromolecules 31, 5559-5562 (1998).

13. Kato, M., Kamigaito, M., Sawamoto, M. and Higashimura, T.: Polymerization of methyl methacrylate with the carbon tetrachloride/dichlorotris(triphenylphosphine)ruthenium(II)/methylaluminum bis(2,6-di-tert-butylphenoxide) initiating system: Possibility of licing radical polymerization. Macromolecules 28, 1721-1723 (1995).

14. Norisuye, T. Morinaga, T. Tran-Cong-Miyata, Q., Goto, A., Fukuda, T., and Shibayama, M.: Comparison of the gelation dynamics for polystyrenes prepared by conventional and living radical polymerizations: a time-resolved dynamic light scattering study. Polymer 46, 1982-1994 (2005).

15. Boonpangrak, S., Whitcombe, M.J.: Prachayasittikul, V., Mosbach, K. and Ye, L. 
Preparation of molecularly imprinted polymers using nitroxide-mediated living radical polymerization. Biosensors \& Bioelectronics 22, 349-354 (2006).

16. Sasaki, S., Ooya, T. and Takeuchi, T.: Highly selective bisphenol A-imprinted polymers prepared by atom transfer radical polymerization. Polymer Chemistry 1, 1684-1688 (2010).

17. Salian, V.D., Vaughan, A.D. and Byrne, M.E.: The role of living/controlled radical polymerization in the formation of improved imprinted polymers. Journal of Molecular Recognition 25, 361-369 (2012).

18. Gai, Q.Q., Qu, F., Liu, Z.J., Dai, R.J. and Zhang, Y.K.: Superparamagnetic lysozyme surface-imprinted polymer prepared by atom transfer radical polymerization and its application for protein separation. Journal of Chromatography A 1217, 5035-5042 (2010).

19. Min, K. and Matyjaszewski, K.: Atom transfer radical polymerization in aqueous dispersed media Cent. Eur. J. Chem. 7, 657-674 (2009).

20. Matyjaszewski, K. and Xia, J.: Atom Transfer Radical Polymerization. Chem. Rev. 101, 2921-2990 (2001).

21. Sunayama, H., Ooya, T. and Takeuchi, T.: Fluorescent Protein Recognition Polymer Thin Films Capable of Selective Signal Transduction of Target Binding Events Prepared by Molecular Imprinting with a Post-Imprinting Treatment, Biosens. Bioelectron. 26, 458-462 (2010). 


\section{Figure legends}

Fig. 1. Film thickness of MIPs on QCM sensor chips versus time plots of (a) MIP-ATRP and (b) MIP-RP. 2-Bromo-2-methylpropionic acid concentration used for immobilization: 0.02 $\mathrm{mM}$ (open circle), $2 \mathrm{mM}$ (open diamond) and $20 \mathrm{mM}$ (open square); V-50 concentration for the immobilization: $10 \mathrm{mM}$ (closed triangle).

Fig. 2 Mass of MIP-ATRP thin films on QCM sensor chips before (black) and after successive washing with $\mathrm{NaCl}$ (gray) and EDTA-4Naq (white). 2-Bromo-2-methylpropionic acid concentration for the immobilization: $20 \mathrm{mM}$; AGET ATRP reaction time: $24 \mathrm{~h}$.

Fig. 3 Binding of RNase to MIP-ATRP (open circle) and MIP-RP (closed circle) on SPR sensor chips. 2-Bromo-2-methylpropionic acid concentration for immobilization: $0.02 \mathrm{mM}$; V-50 concentration for the immobilization: $10 \mathrm{mM}$; AGET ATRP reaction time: $4.5 \mathrm{~h}$; RP reaction time: $12 \mathrm{~h}$.

Fig. 4 Binding of RNase, Cyt, Myo, and Lac to MIP-ATRP prepared on SPR chips (0.02 mM 2-bromo-2-methylpropionic acid concentration; (a) $3 \mathrm{~h}$, (b) $4.5 \mathrm{~h}$, and (c) $6 \mathrm{~h}$ polymerization times). Protein concentration: $1 \mu \mathrm{M}$.

Fig. 5 Binding of RNase, Cyt, Myo, and Lac on MIP-ATRP prepared on SPR chips (20 mM 2-bromo-2-methylpropionic acid concentration; (a) $3 \mathrm{~h}$, (b) $6 \mathrm{~h}$, and (c) $12 \mathrm{~h}$ polymerization times). Protein concentration: $1 \mu \mathrm{M}$.

Fig. 6 Binding of RNase, Cyt, Myo, and Lac on MIP-RP prepared on SPR chips (10 mM V-50 concentration; $3 \mathrm{~h}, 6 \mathrm{~h}$, and $12 \mathrm{~h}$ polymerization times). Protein concentration: $1 \mu \mathrm{M}$. 

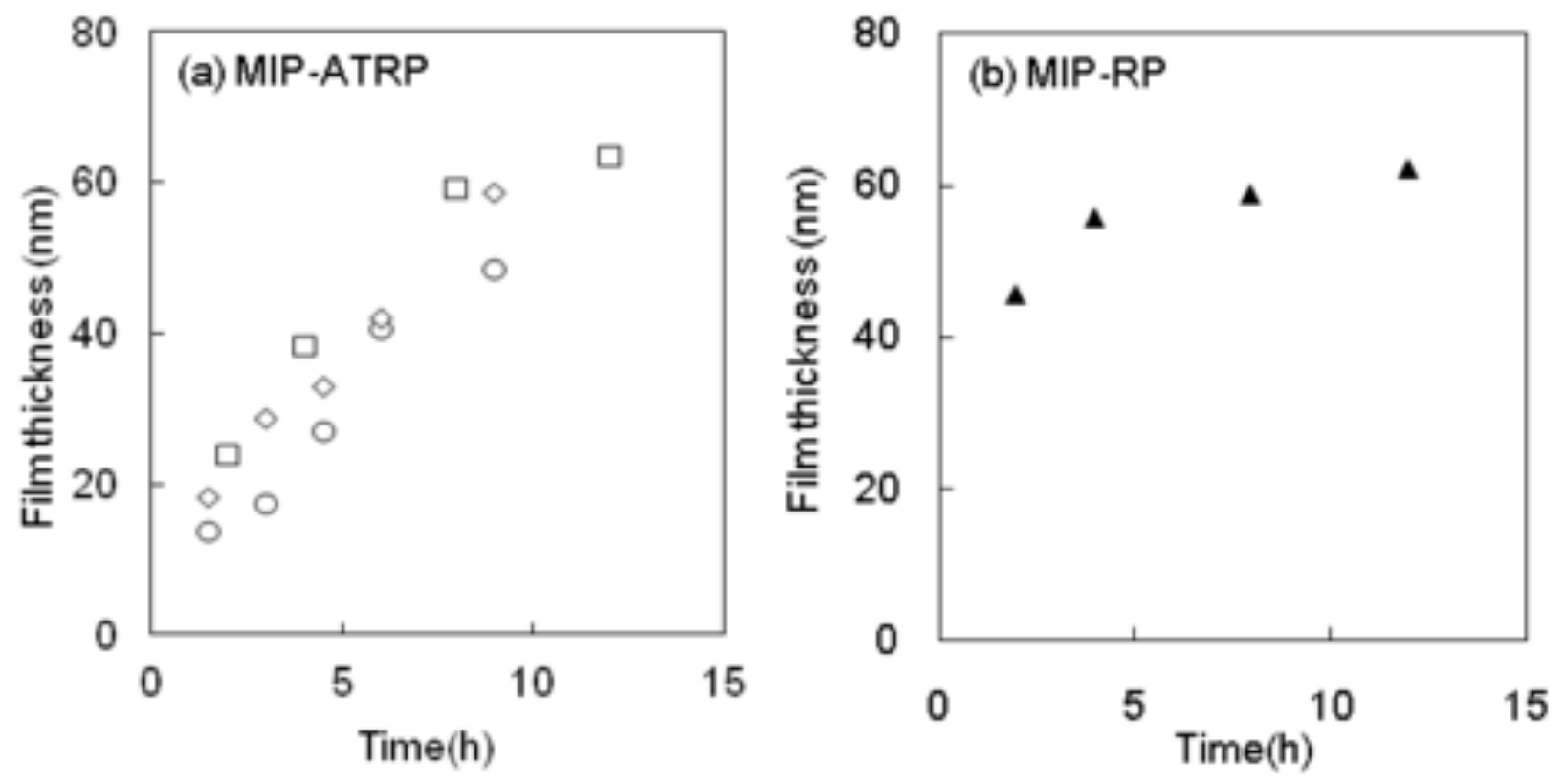


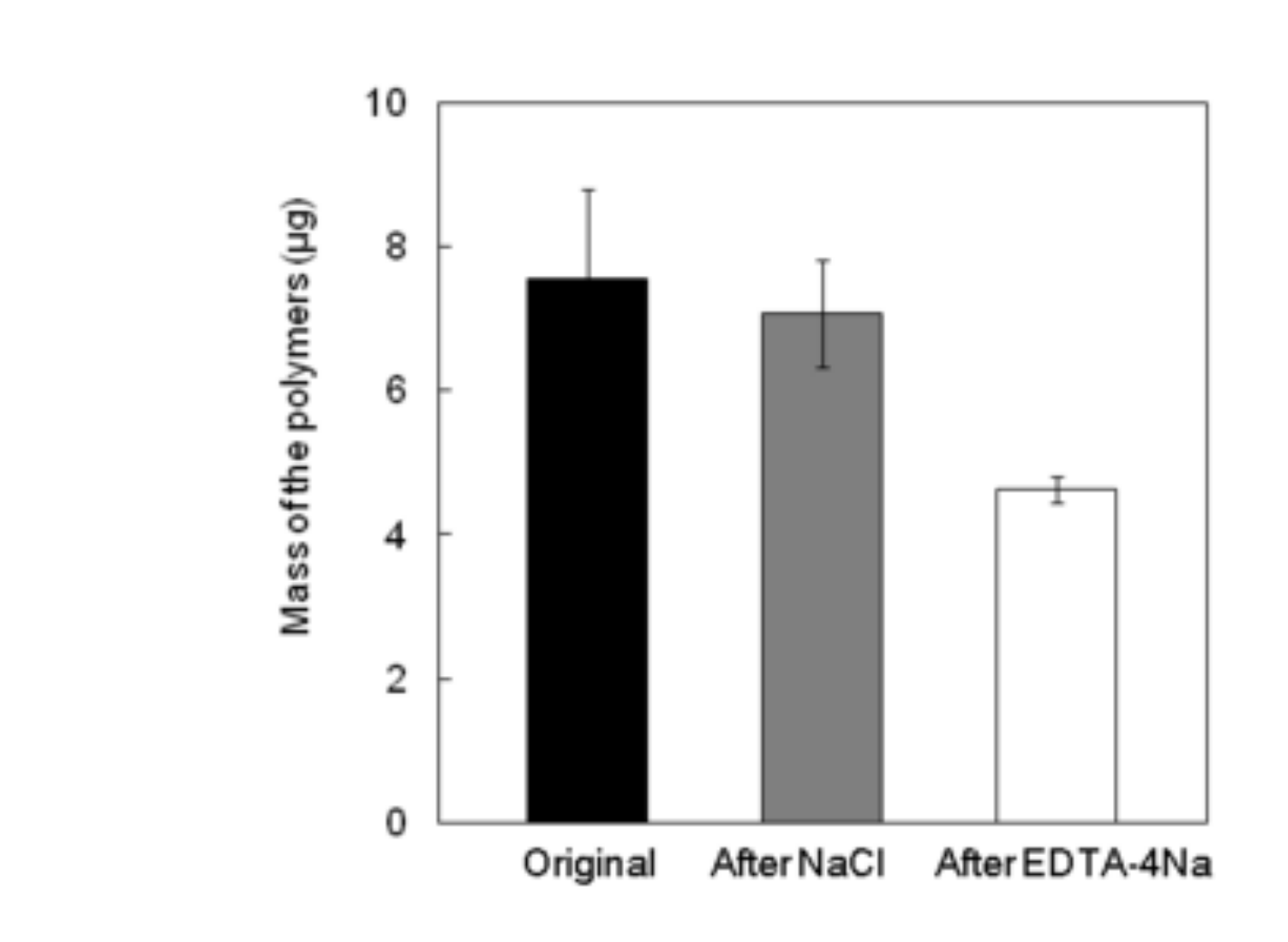

Figure 2

Original AfterNaCl AferEDTA $4 \mathrm{Na}$

Figure 2

2



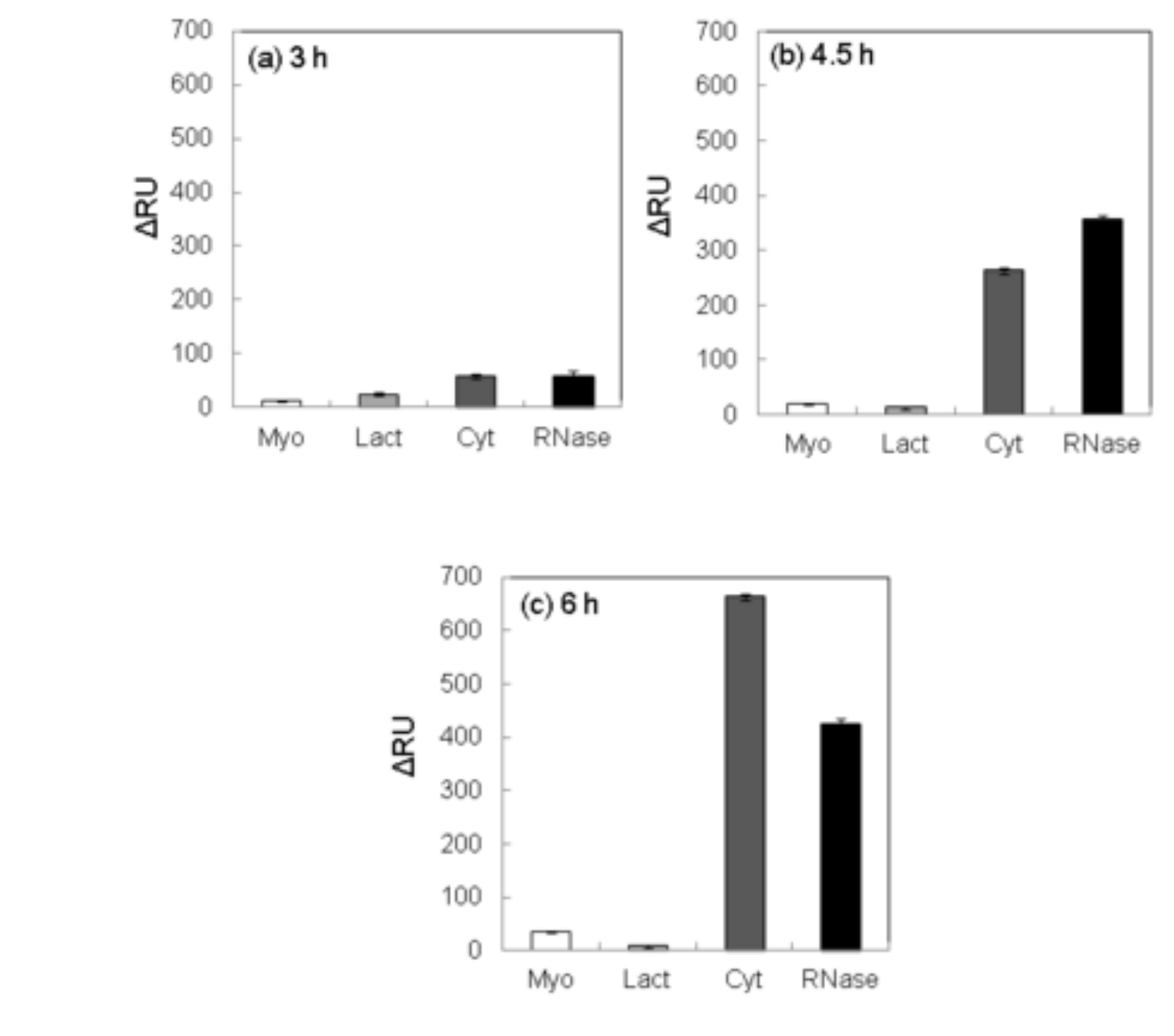

Figure 4

gure 4 

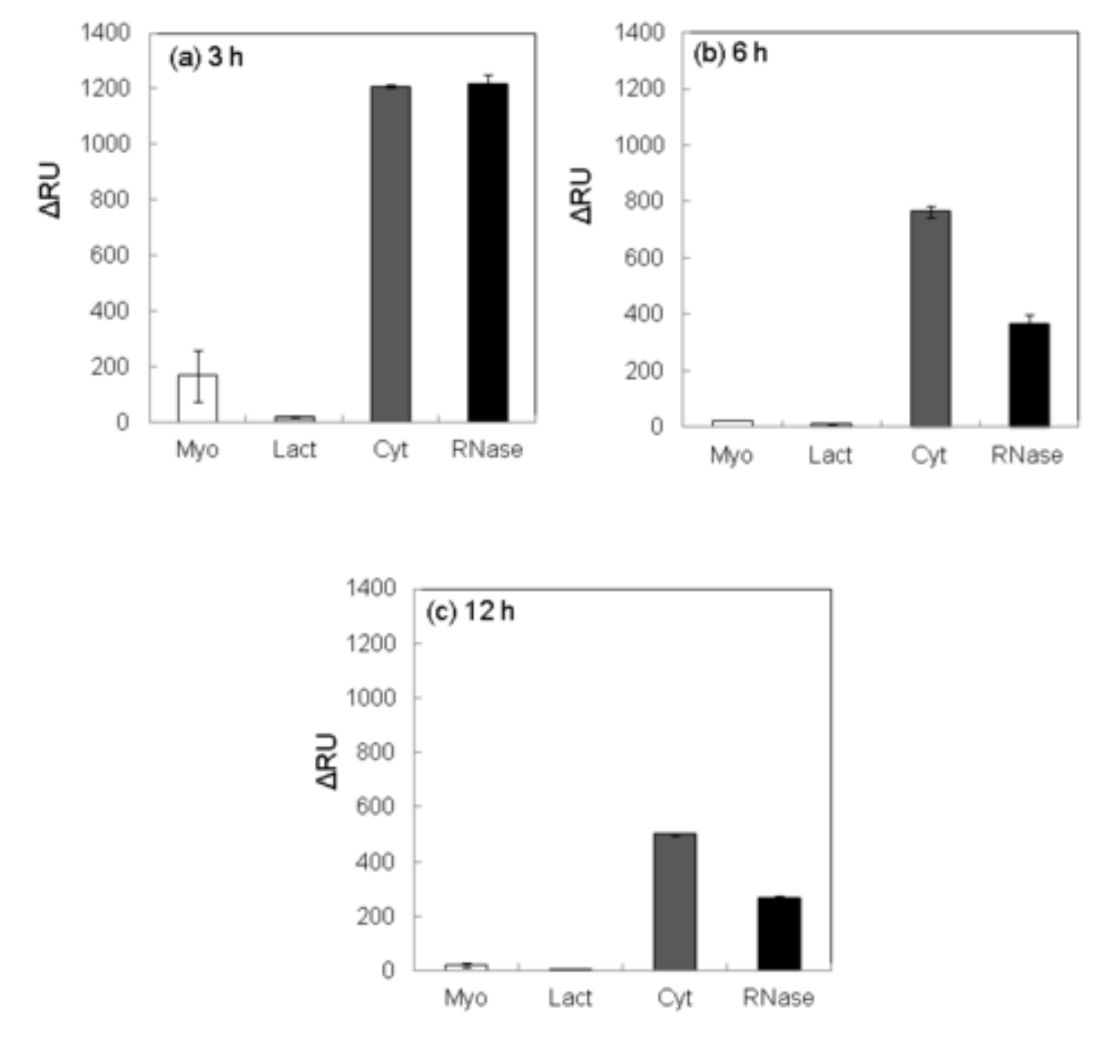

Figure 6

Figure 6 